\title{
Evaluation of Dimensional Stability of Different Solvents for Alginate
}

\author{
P.Keshaav Krishnaa ${ }^{1}$ and A. Sumathi Felicita ${ }^{2}$ \\ ${ }^{1}$ Saveetha Dental College, Saveetha Institute of Medical and \\ Technical Sciences, Saveetha University, Chennai-77, India \\ ${ }^{2}$ Reader Department of Orthodontics, Saveetha Dental College, Saveetha Institute of \\ Medical and Technical Sciences, Saveetha University, Chennai-77, India
}

\section{ABSTRACT}

Alginate impression materials are easy to use, less expensive, with quick setting time and are the most commonly used material for dental impressions. However there has not been any research into different solvents which can be used along with alginate.The aim of the study is to determine the dimensional stability alginate when mixed with different solvents as part of impression making.40 samples were fabricated in total among the four groups. The grouping was done randomly with different solvents such as water, water with glucose, water with glucose and starch and saline.Once the samples were obtained, with the help of a vernier calliper the diameter and thickness of the cylinder is measured. A stopwatch was maintained and the measurements were repeated after every four minutes by the same practitioner. On analysing the dimensional variations that was observed, it was noted that water along with glucose and starch had minimal dimensional changes and proved better than conventionally used water as well. Within the limits of the present study it is evident that the newly developed solvent for alginate has better dimensional stability than conventionally used solvents which shows a statistically significant result using ANOVA ( $p=0.007)$, However, dimensional stability is not the only property that is needed from an impression material and hence this paves way for further studies in the same which can improve the quality of care that is administered to the entire society.

\section{KEY WORDS: DIMENSIONAL CHANGES, ALGINATE, SOLVENTS.}

\section{INTRODUCTION}

Alginate dental impression materials were introduced into dental practice at about 1940(Nallamuthu, Braden and Patel, 2012). Since their introduction they have been used extensively in dentistry for various purposes as one of the group of so-called 'elastic' impression materials, with well documented advantages and disadvantages (Craig and Powers, 2002; Van Noort, 2002; Kenneth J. Anusavice, Shen and Ralph Rawls, 2012)as well as certain

\section{ARTICLE INFORMATION}

*Corresponding Author: sumathifelicita@saveetha.com Received 30th July 2020 Accepted after revision 19th Sep 2020 Print ISSN: 0974-6455 Online ISSN: 2321-4007 CODEN: BBRCBA

Thomson Reuters ISI Web of Science Clarivate Analytics USA and Crossref Indexed Journal

\section{Clarivate
Analytics}

NAAS Journal Score 2020 (4.31) SJIF: 2020 (7.728)

A Society of Science and Nature Publication,

Bhopal India 2020. All rights reserved.

Online Contents Available at: http//www.bbrc.in/

Doi: http://dx.doi.org/10.21786/bbrc/13.8/196 developments. Alginate has further found widespread application in ophthalmic surgery (Mathews et al., 2000) and in estimating wound size in case of general surgery (Plassmann, Melhuish and Harding, 1994).

The term 'elastic' which is used to describe alginate however is something of a misnomer as alginates are considered to be visco-elastic materials with rubberlike compliance. Since their inception, there have been numerous of publications on a their mode of usage as well as their properties (Buchan and Peggie, 1966; Murata et al., 2004; Frey, Lu and Powers, 2005; King et al., 2008; Lawson, Burgess and Litaker, 2008; Walker et al., 2010). However, they have been almost exclusively used only on commercial products. Cook (Cook, 1986) investigated the effect of certain substances on properties, by using commercially available impression materials and analyzing them for parameters to explain the results of a number of physical tests. Morris (Morris, 1986)

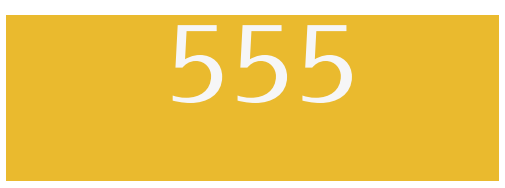


studied the chemical structure of alginate polymers to investigate the role of individual components in alginate impression materials and the effect of these components on physical properties, formulations have to be produced with time.

Alginate impression materials are easy to use, less expensive, with quick setting time. The setting time can be controlled with the temperature of water used. They are mildly flavored. Their disadvantages include less accurate reproduction of details as compared with elastomeric impression materials, poor dimensional stability, and that they are messy to work with. Water has been used as the solvent for alginate since the introduction of the material and there has not been any research that has been done to determine other solvents for alginate as an impression material.Our extensive research expertise ranged from epidemiological studies to randomised clinical trials that have been published in reputed journals (Felicita, 2017a, 2017b, 2018; Felicita, Thirumurthi and Jain, 2017; Korath, Padmanabhan and Parameswaran, 2017; Krishnan, Pandian and Rajagopal, 2017; Charles et al., 2018; Pandian, Krishnan and Kumar, 2018; Reddy et al., 2018; Chinnasamy et al., 2019). This knowledge was instrumental for us to study the solvents for alginate. The aim of the study is to determine the dimensional stability of alginate when mixed with different solvents as part of impression making. .

\section{MATERIAL AND METHODS}

A mould was fabricated with the help of a putty index with a $5 \mathrm{~cm}$ radius, for fabricating the alginate samples. 40 samples were fabricated in total among the four groups. The grouping was done randomly with different solvents such as water, water with glucose, water with glucose and starch and saline. These solvents were chosen for the present study based on a previous study which assessed the patient's perception towards the different solvents. Once the solvent was chosen, alginate was manipulated appropriately by a single practitioner to eliminate the operator bias. Two minutes after the mixture had set, the sample was removed from the mould.

Figure 1: Image shows depiction of the diameter of the constructed structure

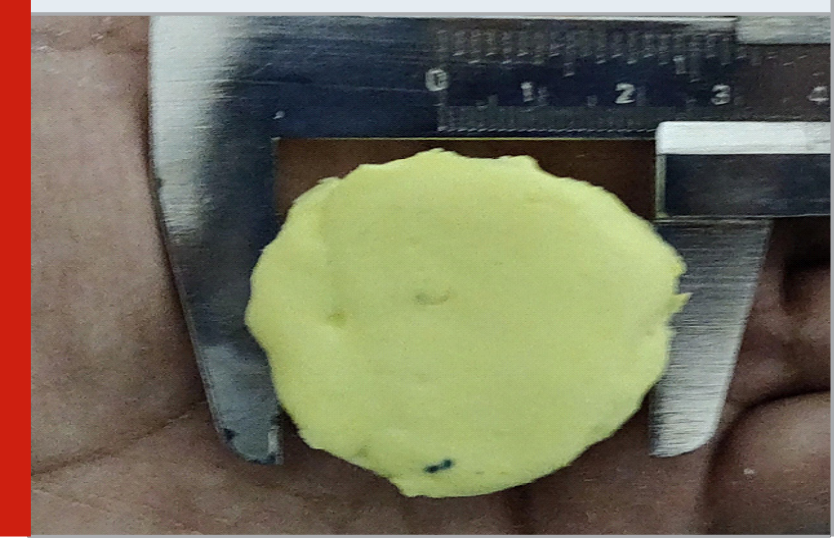

Figure 2: Image shows measurement of thickness with the help of a vernier calliper.

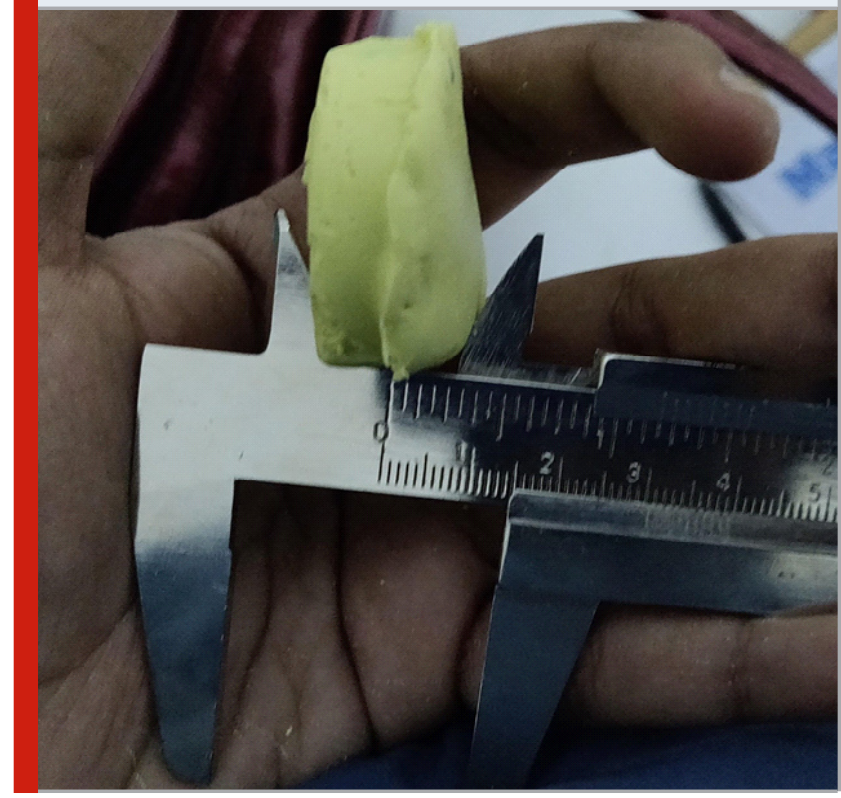

Once the samples were obtained, with the help of vernier callipers the diameter and thickness of the cylinder is measured. A stopwatch was maintained and the measurements were repeated after every four minutes by the same practitioner. The readings were then tabulated and the values were tabulated. ANOVA test was done to compare the outcome between the four groups at different time intervals with the level of significance set at $\mathrm{p} \leq 0.5$.

\section{RESULTS AND DISCUSSION}

When the samples were assessed for dimensional stability within the time duration, changes in both the axis were recorded and the same was tabulated and subjected to statistical testing. The mean difference from both the axis under the different time intervals are tabulated in Table 1

From Table 1 it is evident that there are dimensional changes that are occurring irrespective of the solvent that is being used but an important factor that is to be identified from the table is that the degree of change in volume changes as per the solvent. At the end of 20 minutes, probably the maximum amount of time that an impression will be left outside before pouring the cast, the solvent with maximum amount of dimensional change is water with glucose which is one of the novel solvent that has been introduced in the present study. On the other hand it is also observed that the least dimensional distortion is observed with water in combination with glucose and starch which is also a solvent that was introduced in the present study. There is lesser distortion than that is observed with water. There is a statistically significant $p=0.007(p<0.05)$ reading on the benefit of these solvents than to conventional solvents using $t$ test. 
Impression materials should be accurate and remain dimensionally stable until cast in a gypsum product. Accuracy is the ability to reproduce a true measured value, and dimensional stability is the ability to maintain accuracy across time. The processes that influence alginate dimensional stability are expansion due to water absorption (imbibition), shrinkage due to evaporation of water and syneresis (continued reaction of the sol). The first two processes depend primarily on storage conditions, and syneresis is affected by the proprietary constituents of the alginate (Buchan and Peggie, 1966).

\begin{tabular}{|c|c|c|c|c|c|}
\hline $\begin{array}{l}\text { Time } \\
\text { Interval }\end{array}$ & Water & $\begin{array}{l}\text { Water with } \\
\text { Glucose }\end{array}$ & $\begin{array}{c}\text { Water with Glucose } \\
\text { and Starch }\end{array}$ & Saline & Significance \\
\hline 4 Minutes & $0.10 \pm 0.003$ & $0.14 \pm 0.007$ & $0.08 \pm 0.001$ & $0.12 \pm 0.002$ & $\mathrm{p}=0.007$ \\
\hline 8 Minutes & $0.18 \pm 0.002$ & $0.20 \pm 0.003$ & $0.12 \pm 0.003$ & $0.16 \pm 0.004$ & \\
\hline 12 Minutes & $0.22 \pm 0.003$ & $0.23 \pm 0.002$ & $0.20 \pm 0.005$ & $0.23 \pm 0.001$ & \\
\hline 16 Minutes & $0.29 \pm 0.008$ & $0.28 \pm 0.004$ & $0.23 \pm 0.002$ & $0.27 \pm 0.005$ & \\
\hline 20 Minutes & $0.32 \pm 0.006$ & $0.35 \pm 0.005$ & $0.29 \pm 0.004$ & $0.31 \pm 0.002$ & \\
\hline
\end{tabular}

Water in an alginate gel is either free or bound. The free water is trapped among the filler particles and is susceptible to volumetric increases or decreases as a result of evaporation or imbibition. The amount of water lost through evaporation may be regained through imbibition (Hohlt and Phillips, 1956). One may speculate that movement of free water is explained easily, but nothing could be further from the truth. Nallamuthu and colleagues (Nallamuthu, Braden and Patel, 2006) explained that water loss depends on diffusion kinetics, decreases in entropy and changes in Gibbs free energy. Furthermore, complex osmotic pressures and gradient changes existing between the gel, sol and environment are specific for different alginate materials depending on proprietary ingredients (Saitoh et al., 2000). Bound water syneresis is the result of a rearrangement of cross-linked alginic polymer chains to a more stable configuration, resulting in exudation of the formerly bound water.

This water movement may occur rapidly even in 100 percent humidity. Using nuclear magnetic resonance spectroscopy and moisture sorption isotherms, Fellows and Thomas (Fellows and Thomas, 2009) proposed that alginate with a higher ratio of calcium to sodium lose water more rapidly than do alginate with a lower ratio of calcium to sodium even though they exhibit greater dimensional stability. In addition, these authors (Fellows and Thomas, 2009) observed improved dimensional stability with alginates that contain higher ratios of filler to alginic polymer and lower-weight molecular polymer chains.

Chromatic alginates such as Cavex Color Change contain additives that control the $\mathrm{pH}$. The initial mix of chromatic alginate usually is alkaline, with a $\mathrm{pH}$ approximating 11 that decreases to near neutrality when set. The influence of these additives on dimensional stability has not been examined, to our knowledge, but it may have a beneficial role. With the above discussion it is evident that there are various factors that can influence the dimensional stability of alginate, further studies are to be performed to improve the amount of data that is available, this in turn would improve the quality of care and perception of patients towards dental practice.

\section{CONCLUSION}

Within the limits of the present study it is evident that the newly developed solvent for alginate has better dimensional stability than conventionally used solvents. However dimensional stability is not the only property that is needed from an impression material and hence this paves way for further studies in the same which can improve the quality of care that is administered to the entire society.

\section{ACKNOWLEDGEMENTS}

We sincerely thank Saveetha Dental College for rendering full support for my study.

\section{Conflict of Interest: Nil}

\section{REFERENCES}

Buchan, S. and Peggie, R. W. (1966) 'Role of Ingredients in Alginate Impression Compounds', Journal of dental research. SAGE Publications Inc, 45(4), pp. 11201129.

Charles, A. et al. (2018) 'Evaluation of dermatoglyphic patterns using digital scanner technique in skeletal malocclusion: A descriptive study', Indian journal of dental research: official publication of Indian Society for Dental Research, 29(6), pp. 711-715.

Chinnasamy, A. et al. (2019) 'Chronic nail biting, orthodontic treatment and Enterobacteriaceae in the oral cavity', Journal of clinical and experimental dentistry, 11(12), pp. e1157-e1162.

Cook, W. (1986) 'Alginate dental impression materials: Chemistry, structure, and properties', Journal of 
biomedical materials research. Wiley Online Library, 20(1), pp. 1-24.

Craig, R. G. and Powers, J. M. (2002) 'Restorative dental materials 11th ed', St. Louis: Mosby, pp. 238-292.

Felicita, A. S. (2017a) 'Orthodontic management of a dilacerated central incisor and partially impacted canine with unilateral extraction - A case report', The Saudi dental journal, 29(4), pp. 185-193.

Felicita, A. S. (2017b) 'Quantification of intrusive/ retraction force and moment generated during enmasse retraction of maxillary anterior teeth using mini-implants: A conceptual approach', Dental press journal of orthodontics, 22(5), pp. 47-55.

Felicita, A. S. (2018) 'Orthodontic extrusion of Ellis Class VIII fracture of maxillary lateral incisor - The sling shot method', The Saudi dental journal, 30(3), pp. 265-269.

Felicita, A. S., Thirumurthi, A. S. and Jain, R. K. (2017) 'Patient's Psychological Response to Twinblock Therapy', World Journal of Dentistry, 8(4), pp. 327-330.

Fellows, C. M. and Thomas, G. A. (2009) 'Determination of bound and unbound water in dental alginate irreversible hydrocolloid by nuclear magnetic resonance spectroscopy', Dental materials: official publication of the Academy of Dental Materials. Elsevier, 25(4), pp. 486-493.

Frey, G., Lu, H. and Powers, J. (2005) 'Effect of Mixing Methods on Mechanical Properties of Alginate Impression Materials', Journal of prosthodontics: official journal of the American College of Prosthodontists. Wiley Online Library, 14(4), pp. 221-225.

Hohlt, F. A. and Phillips, R. W. (1956) 'Evaluation of various methods employed for constructing working dies from hydrocolloid impressions', The Journal of prosthetic dentistry. thejpd.org. Available at: https:// www.thejpd.org/article/0022-3913(56)90037-3/pdf.

Kenneth J. Anusavice, D., Shen, C. and Ralph Rawls, H. (2012) Phillips' Science of Dental Materials. Elsevier Health Sciences.

King, S. et al. (2008) 'Determining the complex modulus of alginate irreversible hydrocolloid dental material', Dental materials: official publication of the Academy of Dental Materials. Elsevier, 24(11), pp. 1545-1548.

Korath, A. V., Padmanabhan, R. and Parameswaran, A. (2017) 'The Cortical Boundary Line as a Guide for Incisor Re-positioning with Anterior Segmental Osteotomies', Journal of maxillofacial and oral surgery, 16(2), pp. 248-252.

Krishnan, S., Pandian, S. and Rajagopal, R. (2017) 'Sixmonth bracket failure rate with a flowable composite: A split-mouth randomized controlled trial', Dental press journal of orthodontics, 22(2), pp. 69-76.

Lawson, N. C., Burgess, J. O. and Litaker, M. (2008) 'Tear Strength of Five Elastomeric Impression Materials at Two Setting Times and Two Tearing Rates', Journal of esthetic and restorative dentistry: official publication of the American Academy of Esthetic Dentistry ... [et al.]. Wiley Online Library, 20(3), pp. 186-193.

Mathews, M. F. et al. (2000) 'The ocular impression: A review of the literature and presentation of an alternate technique', Journal of prosthodontics: official journal of the American College of Prosthodontists. Wiley Online Library, 9(4), pp. 210-216.

Morris, E. R. (1986) 'Molecular Interactions in Polysaccharide Gelation', British Polymer Journal. Wiley Online Library, 18(1), pp. 14-21.

Murata, H. et al. (2004) 'Physical properties and compatibility with dental stones of current alginate impression materials', Journal of oral rehabilitation. Wiley Online Library, 31(11), pp. 1115-1122.

Nallamuthu, N. A., Braden, M. and Patel, M. P. (2012) 'Some aspects of the formulation of alginate dental impression materials-Setting characteristics and mechanical properties', Dental materials: official publication of the Academy of Dental Materials. Elsevier, 28(7), pp. 756-762.

Nallamuthu, N., Braden, M. and Patel, M. P. (2006) 'Dimensional changes of alginate dental impression materials', Journal of materials science. Materials in medicine. Springer, 17(12), pp. 1205-1210.

Pandian, K. S., Krishnan, S. and Kumar, S. A. (2018) 'Angular photogrammetric analysis of the soft-tissue facial profile of Indian adults', Indian journal of dental research: official publication of Indian Society for Dental Research, 29(2), pp. 137-143.

Plassmann, P., Melhuish, J. M. and Harding, K. G. (1994) 'Methods of measuring wound size: a comparative study', Ostomy/wound management. europepmc.org, 40(7), pp. 50-52.

Reddy, A. K. et al. (2018) 'Comparative Evaluation of Antimicrobial Efficacy of Silver, Titanium Dioxide and Zinc Oxide Nanoparticles against Streptococcus mutans', Pesquisa brasileira em odontopediatria e clinica integrada, 18(1), p. e4150.

Saitoh, S. et al. (2000) 'Swelling/deswelling Mechanism of Calcium Alginate Gel in Aqueous Solutions', Dental materials journal. jstage.jst.go.jp, 19(4), pp. 396-404. Van Noort, R. (2002) 'Introduction to Dental Materials.“2nd Ed.”, St. Louis: Mosby, Chapters, 1(3.3).

Walker, M. P. et al. (2010) 'Dimensional change over time of extended-storage alginate impression materials', The Angle orthodontist. Allen Press, 80(6), pp. 1110-1115. 